\title{
Development of Fe-B Based Bulk Metallic Glasses: Morphology of Residual Phases in $\mathrm{Fe}_{50} \mathrm{Ni}_{16} \mathrm{Mo}_{6} \mathrm{~B}_{18} \mathrm{Zr}_{10}$ Glass
}

\section{Tiburce A. Aboki}

Laboratoire de Physico-Chimie des Surfaces, Groupe de Métallurgie Structurale, UMR 7045, ENSCP, 11 rue Pierre et Marie Curie, F-75231 Paris cedex 05, France;

E-Mail: tiburce-aboki@chimie-paristech.fr; Tel.: +33-144-276-709; Fax: +33-144-276-710.

Received: 30 November 2012; in revised form: 19 March 2013 / Accepted: 26 March 2013 /

Published: 9 April 2013

\begin{abstract}
Iron-boron based bulk metallic glasses (BMG) development has been initiated using $\mathrm{Fe}_{40} \mathrm{Ni}_{38} \mathrm{Mo}_{4} \mathrm{~B}_{18}$ as precursor. Addition of zirconium up to 10 atomic \% along with the reduction of $\mathrm{Ni}$ proportion improves the glass forming ability (GFA), which is optimum when $\mathrm{Ni}$ is suppressed in the alloy. However melting instability occurred during the materials fabrication resulting in the formation of residual crystalline phases closely related to the amorphous phase. Microstructure study shows an evolution from amorphous structure to peculiar acicular structure, particularly for $\mathrm{Fe}_{50} \mathrm{Ni}_{16} \mathrm{Mo}_{6} \mathrm{~B}_{18} \mathrm{Zr}_{10}$, suggesting the amorphous structure as interconnected atomic sheets like "atomic mille feuilles" whose growth affects the alloys' GFA.
\end{abstract}

Keywords: bulk metallic glass; eutectic alloys; critical cooling; wrinkles

\section{Introduction}

Bulk metallic glasses still have promising applications owing to their remarkable properties [1], although the size limitations have not been overcome. As regards applications, casing for high technology devices and corrosion resistance as for instance Zr-based BMG [2], can be foreseen despite their high production costs. For the compositions of BMG, Fe-based alloys have higher potential for magnetic devices [3]. However, major breakthroughs are expected to raise understanding of the formation of the metallic amorphous structure significantly, which will lead to the designing of easy processing techniques. These need probably to redefine the way we were mentally describing the atomic organization in metallic amorphous structure with regard to crystal and liquid. Whatever the importance of the physical properties is, there will be a necessity to access the microstructure's 
description, which can only improve our understanding of the atomic arrangement in the BMGs. Moreover, microstructural patterns, morphologies must be explained not only referring to known features in materials science but from other scientific areas, like at the eve of physical metallurgy, for instance, where the peculiar microstructure of martensite was established [4]. This procedure is applied to the work, which is the scope of this paper.

As in that earlier study [5], we have initiated the development of Fe-B-based BMG choosing $\mathrm{Zr}$ as additional element to enhance the glass forming ability GFA [3] of an initial $\mathrm{Fe}_{40} \mathrm{Ni}_{38} \mathrm{Mo}_{4} \mathrm{~B}_{18}$ alloy. This latter is commercially known as Metglas $2605 \mathrm{MB}$, yields good ribbons, crystallizes primarily in metastable cubic $\mathrm{Fe}_{x} \mathrm{Ni}_{23}{ }_{-x}(\mathrm{Mo}) \mathrm{B}_{6}$ [6,7], a melt stability criterion according to Jones [8], that directs its choice as precursor material for development of BMG. The GFA of the processed materials: ribbons, strips, and ingots were evaluated by the $\Delta T x=T x-T g$ parameter, where $T x$ is the onset crystallization temperature and $T g$ the glass transition temperature, obtained by thermal analysis experiments. Most importantly, the microstructure's evolution was observed in $\mathrm{Fe}_{m} \mathrm{Ni}_{n} \mathrm{Mo}_{6} \mathrm{~B}_{18} \mathrm{Zr}_{10}$ alloys with $m=50,66$ and $n=16$ and 0 , two selected compositions among those studied, following the cooling rate established within the different ingots. Morphologies of residual crystalline phases in the amorphous matrix and within the off-amorphous materials microstructure suggest that amorphous microstructure are formed by interconnected atomic "mille feuilles" like sheets, or atomic foils, probably the liquid-like structure, which grew into lamella and needles hierarchically following the quenching rate.

A descriptive microstructural model of the amorphous structure (MMAS) is presented based on wrinkled atomic layers supported by observed microstructure patterns. It is also admitted that the patterns are footprints leaved in the microstructure by the glass forming melt. The model accounts for the mechanical effects on the formation of the amorphous structure.

Additional guidelines signs (Figure 1) are introduced in this paper in order to help the reader spot the peculiar features, morphologies and patterns within the described microstructure. Since our description is uncommon, careful attention should be paid to the microstructure as we have done ourselves.

Figure 1. Guidelines signs to spot the peculiar features within the described microstructures.

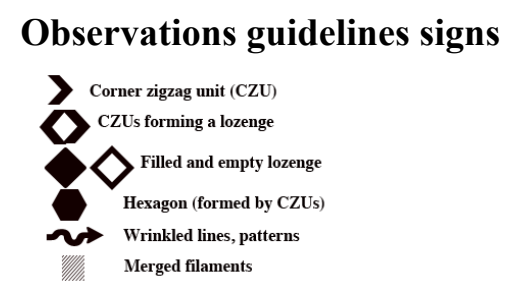

\section{Results and Discussion}

\subsection{Microstructure of Injected $\mathrm{Fe}_{40} \mathrm{Ni}_{38} \mathrm{Mo}_{6} \mathrm{~B}_{18}$ Alloy}

Figure 2 shows the SEM-BEI micrographs of $\mathrm{Fe}_{40} \mathrm{Ni}_{38} \mathrm{Mo}_{4} \mathrm{~B}_{18}$ plate ingot cross section. It is crystalline with a major eutectic structure containing white contrast precipitates and dendrites. These latter are formed on linear paths that are probably linked to the turbulent movement of the melt during 
the casting (Figure 2a). Details of the eutectic grains (Figure 2b), with one phase appearing as a needle are shown (white arrowed) along with dots (black arrowed). The dot is presumably the same needle's front view. The dendrites and the plate-like precipitates embedded in the eutectic matrix are also magnified in Figure 2c. The eutectic structure is composed of cubic (c) (Fe, Ni) and orthorhombic (o) $(\mathrm{Fe}, \mathrm{Ni}, \mathrm{Mo})_{3} \mathrm{~B}$ phases, the nature of the plate precipitates are much complex. It has been characterized as tetragonal (t) Fe-Mo sigma phase [9], however c- $\mathrm{Fe}_{2} \mathrm{Mo}_{3}$ phase and other unknown Mo-rich phases can match. The dendrite axis is also tricky because of its content in boron. They can be described as $\mathrm{c}-\mathrm{Fe}_{x} \mathrm{Ni}_{23}-{ }_{x}(\mathrm{Mo}) \mathrm{B}_{6}$ or/and $\mathrm{B}-\mathrm{Mo}$ rich phases. A detailed study of the crystalline phases in $\mathrm{Fe}_{40} \mathrm{Ni}_{38} \mathrm{Mo}_{4} \mathrm{~B}_{18}$ alloy will be published further elsewhere.

Figure 2. (a) SEM-BEI micrographs of $\mathrm{Fe}_{40} \mathrm{Ni}_{38} \mathrm{Mo}_{4} \mathrm{~B}_{18}$ plate ingot sample processed by levitation; (b) Needle-like phase in the eutectic microstructure; (c) Plate-like crystals and dendrites embedded in the eutectic structure.

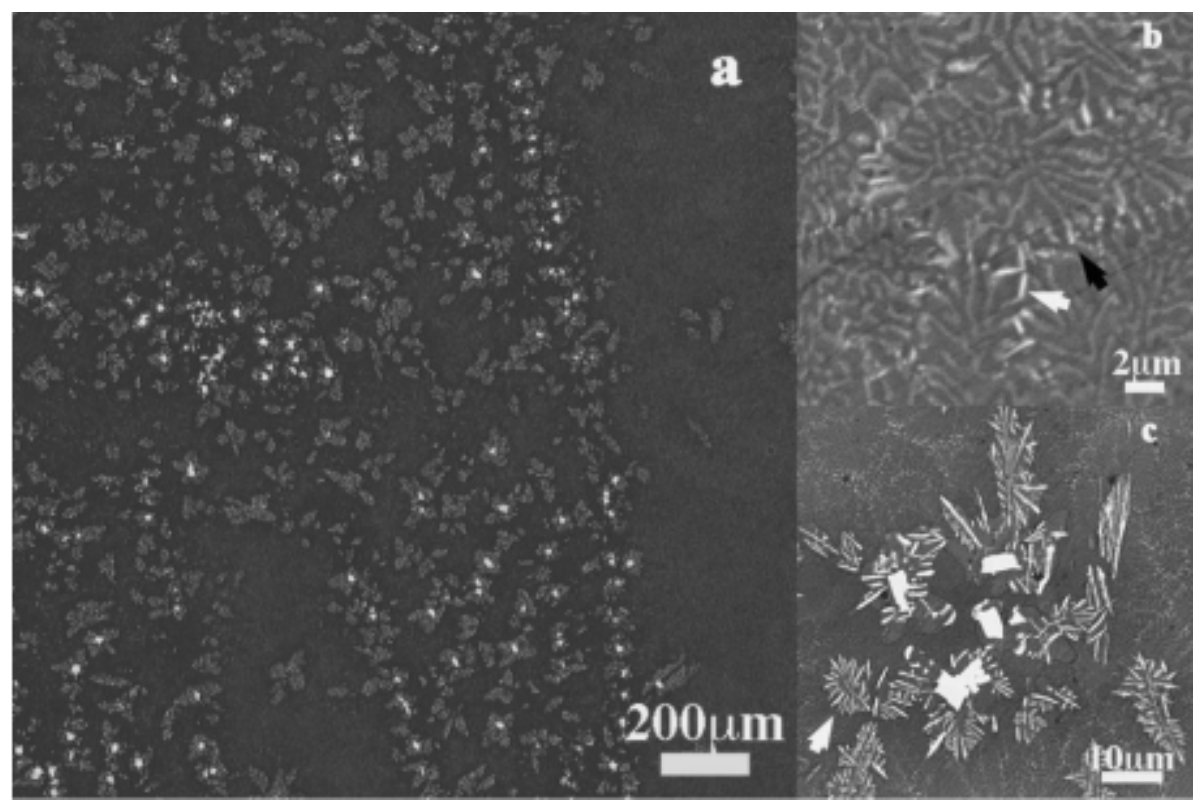

The microstructural inhomogeneity is likely inherent to levitation casting and injected melt casting produced by the unsteady solidification. However, for a homogeneous melt, the stream must have the same composition as the initial melt. The crystalline phases appearing on the paths are the growth of atomic clusters existing within the homogeneous areas due to cooling rate change if one considers that melt filets or filaments generated by the injection pressure have the same chemical composition. Thus, the growth of the crystal may be attributed to the low cooling rate due to higher fluidity, or low viscosity as $\mathrm{d} T / \mathrm{d} t$ is proportional to $1 / \eta$; $\eta$ is the viscosity [10].

\subsection{Microstructure of $\mathrm{Fe}_{45} \mathrm{Ni}_{21} \mathrm{Mo}_{6} \mathrm{~B}_{18} \mathrm{Zr}_{10}$ (Zrl) Master Ingot}

Figure 3 shows SEM-BEI micrographs of $\mathrm{Fe}_{45} \mathrm{Ni}_{21} \mathrm{Mo}_{6} \mathrm{~B}_{18} \mathrm{Zr}_{10} 10 \mathrm{~mm}$ master ingot. The alloy is mainly eutectic with inclusions of the white precipitates within one of the eutectic phase, the light grey one. Fine elongated and equiaxed grains are observed in the outer areas (Figure 3a) while coarsening appeared in the center (Figure 3b) of the ingot. The white-contrasted phases are located preferentially within the light grey phase. The morphologies of the eutectic phases, elongated or equiaxed are due to 
the growth directions. No dendrites are found in the microstructure compared to $\mathrm{Fe}_{40} \mathrm{Ni}_{38} \mathrm{Mo}_{4} \mathrm{~B}_{18}$ alloy. Amorphous ribbons were processed from such master ingots' microstructure.

Figure 3. SEM-BEI micrographs of the cross section of $\mathrm{Fe}_{50} \mathrm{Ni}_{16} \mathrm{Mo}_{6} \mathrm{~B}_{18} \mathrm{Zr}_{10}$ master ingot processed in water-cooled copper boat. (a) Columnar and equiaxed eutectic patterns of the border area; (b) Coarse grained eutectic in the center of the ingot.

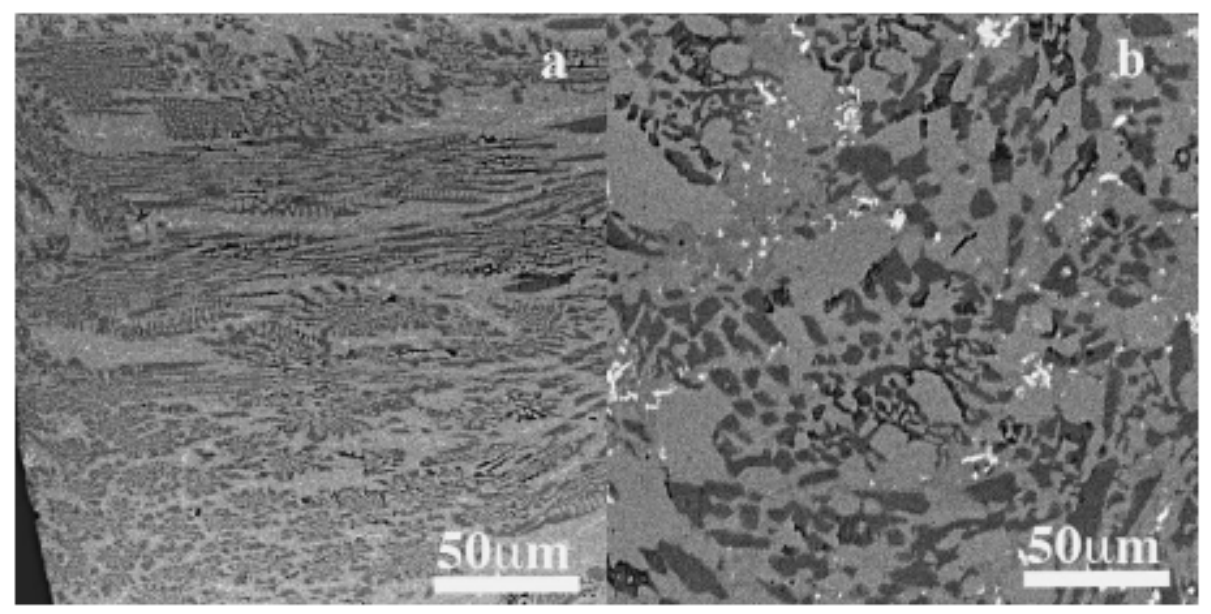

\subsection{Characteristics of $\mathrm{Fe}_{45} \mathrm{Ni}_{21} \mathrm{Mo}_{6} \mathrm{~B}_{18} \mathrm{Zr}_{10}(\mathrm{Zr} \mathrm{l})$ and $\mathrm{Fe}_{50} \mathrm{Ni}_{16} \mathrm{Mo}_{6} \mathrm{~B}_{18} \mathrm{Zr}_{10}$ (Zr2) Amorphous Ribbons}

XRD diffraction patterns of $\mathrm{Fe}_{45} \mathrm{Ni}_{21} \mathrm{Mo}_{6} \mathrm{~B}_{18} \mathrm{Zr}_{10}(\mathrm{Zr} 1)$ and $\mathrm{Fe}_{50} \mathrm{Ni}_{16} \mathrm{Mo}_{6} \mathrm{~B}_{18} \mathrm{Zr}_{10}$ (Zr2) amorphous ribbons are reported in Figure $4 \mathrm{a}$ along with that of $\mathrm{Fe}_{40} \mathrm{Ni}_{38} \mathrm{Mo}_{4} \mathrm{~B}_{18}$ (Pr) ribbon. It is clearly shown that the position of the amorphous halo is shifted towards lower Bragg angle demonstrating the structural contribution of $\mathrm{Zr}$ atoms in the alloys. The position of the halo has a wave vector $K \mathrm{p}=29.85 \mathrm{~nm}^{-1}, K \mathrm{p}=4 \pi \sin \theta / \lambda$ with $\lambda, \mathrm{X}$-rays wavelength; $\theta$, the Bragg angle. This corresponds to the most probable interplanar spacing of about $0.210 \mathrm{~nm}$ compared to that of $0.203 \mathrm{~nm}$ for $\operatorname{Pr}$. Choosing an interval distance around the peak position as for instance a range of 41-45 (20) for Zr1 and $\mathrm{Zr} 2$ ribbons, corresponding to the interplanar spacings of about 0.219-0.201 nm. Similarly, interplanar spacings of about 0.205-0.201 nm are obtained for Pr for a range of Bragg angle of 44-45 (20). These distances can be associated to presumable metastable or/and stable crystalline phases occurring during crystallization of these ribbons, for instance, $\mathrm{Fe} \alpha, \mathrm{c}-\mathrm{Fe}_{2} \mathrm{Zr}$ and $c-\mathrm{Fe}_{x} \mathrm{Ni}_{23-x}(\mathrm{Mo}) \mathrm{B}_{6}$. This suggestion fuels the belief that the halo is not representative of the distance between individual atoms but rather group of atoms of a given family of plane, at least at a scale length of about $0.5-1 \mathrm{~nm}$. Thus for a given atom, for instance Fe, the alloying element would be inserted in dense $(0,1,1)$, and reduces its length by fragmentation in stair-like or zigzag.

The thermal behavior reported in Figure $4 \mathrm{~b}$ confirmed the amorphous nature of the ribbons. Pr does not exhibit a glass transition on the DSC curve after the structural relaxation. The two peaks (I) and (II) correspond respectively to the first and second steps of crystallization. The $\mathrm{Zr}$ content alloys clearly show endothermic trend (see rectangle on Figure $4 \mathrm{~b}$ ) of classical glass transition stage. The glass transition temperatures are about respectively $813 \mathrm{~K}$ and $805 \mathrm{~K}$ for $\mathrm{Zr} 1$ and $\mathrm{Zr} 2$ while the onset of the crystallization temperatures are about $879 \mathrm{~K}$ and $893 \mathrm{~K}$ giving a $\Delta T x$ of $66 \mathrm{~K}$ and $88 \mathrm{~K}$ (Table 1). This latter value is used to select $\mathrm{Zr} 2$ as best candidate for BMG processing since no difference is found between the half width values $(\theta)$ of the X-rays diffraction haloes of the two alloys. 
Figure 4. (a) $\mathrm{XRD}$ patterns of $\mathrm{Fe}_{45} \mathrm{Ni}_{21} \mathrm{Mo}_{4} \mathrm{~B}_{18} \mathrm{Zr}_{10}(\mathrm{Zr} 1), \mathrm{Fe}_{50} \mathrm{Ni}_{16} \mathrm{Mo}_{4} \mathrm{~B}_{18} \mathrm{Zr}_{10}(\mathrm{Zr} 2)$ and $\mathrm{Fe}_{40} \mathrm{Ni}_{38} \mathrm{Mo}_{4} \mathrm{~B}_{18}$ (Pr) ribbons. (b) DSC curves of $\mathrm{Fe}_{45} \mathrm{Ni}_{21} \mathrm{Mo}_{4} \mathrm{~B}_{18} \mathrm{Zr}_{10}, \mathrm{Fe}_{50} \mathrm{Ni}_{16} \mathrm{Mo}_{4} \mathrm{~B}_{18} \mathrm{Zr}_{10}$ and $\mathrm{Fe}_{40} \mathrm{Ni}_{38} \mathrm{Mo}_{4} \mathrm{~B}_{18}$ ribbons.
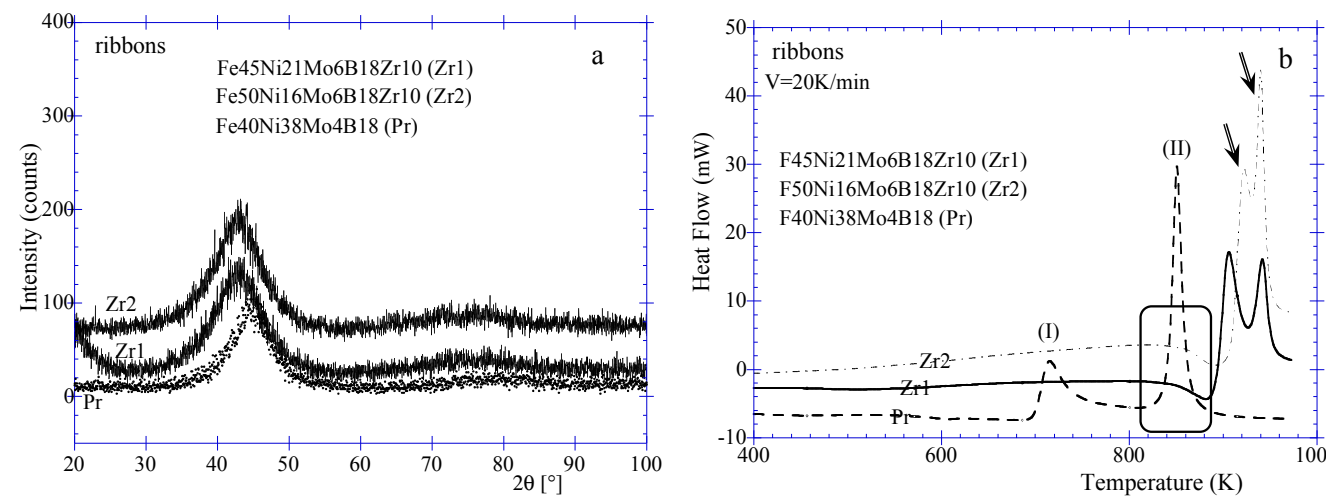

Table 1. Characteristic thermal parameters of processed $\mathrm{Fe}_{m} \mathrm{Ni}_{n} \mathrm{Mo}_{6} \mathrm{~B}_{18} \mathrm{Zr}_{10}$ amorphous with $m=45,50,66 ; n=21,16,0$; in: ribbon (R), wedge ingot (W), strip (S).

\begin{tabular}{cccc}
\hline Alloys composition (at \%) & $\boldsymbol{T g}(\mathbf{K})$ & $\boldsymbol{T} \boldsymbol{x}(\mathbf{K})$ & $\Delta \boldsymbol{T} \boldsymbol{x}(\mathbf{K})$ \\
\hline $\mathrm{Fe}_{45} \mathrm{Ni}_{21} \mathrm{Mo}_{6} \mathrm{~B}_{18} \mathrm{Zr}_{10}(\mathrm{R})$ & 813 & 879 & 66 \\
$\mathrm{Fe}_{50} \mathrm{Ni}_{16} \mathrm{Mo}_{6} \mathrm{~B}_{18} \mathrm{Zr}_{10}(\mathrm{R}, \mathrm{W}, \mathrm{S})$ & $(805,842,834)$ & $(893,898,895)$ & $(88,53,64)$ \\
$\mathrm{Fe}_{66} \mathrm{Mo}_{6} \mathrm{~B}_{18} \mathrm{Zr}_{10}(\mathrm{~S})$ & 853 & 932 & 79 \\
\hline
\end{tabular}

We can conclude that the segregation occurring in the multi-eutectic glass-forming alloy does not impede the amorphous ribbon formation. The homogeneity of the melt is quite maintained in terms of the presence of all probable phases. The shift of the X-rays haloes to lower Bragg angle and its broadening can be attributed to the occurrence of a new probable chemical phase involving $\mathrm{Zr}$ atoms.

\subsection{Microstructures of Wedged and Cylindrical Ingots of $\mathrm{Fe}_{50} \mathrm{Ni}_{16} \mathrm{Mo}_{6} \mathrm{~B}_{18} \mathrm{Zr}_{10}(\mathrm{Zr} 2)$ Alloy: Needles and Lamella}

The wedged ingot (W) obtained from $\mathrm{Zr} 2$ is not fully amorphous. The microstructure of the cross section at about half height of the ingot (Figure 17) is presented in Figure 5 that represents the half section length $(1 / 2 \mathrm{~L})$. On the micrograph, the black arrow indicates the inward evolution of the microstructure. Only the peripheral area is amorphous over about $0.6 \mathrm{~mm}$. At this distance, from the left side, annular-type grains are observed with variable size from 200-300 nm, probably less. This morphology reaches a size of about $2 \mu \mathrm{m}$ close to the center where it reduces into a dot or into a plain disk with a diameter less than $100 \mathrm{~nm}$. From the top, very thin needles are observed that grow inward where they mix with the annular grains. The needles reach the length of about $4 \mu \mathrm{m}$. Additional lenticular grains of about $2 \mu \mathrm{m}$ length that sometimes cross in four-axes dendrites-like are observed. It must be noted that this microstructure is slightly different at other heights of the ingot and exhibits stream paths like in Figure 2. Additional microstructures of this ingot are presented in supplementary materials (SuMat) (see Figures S1 and S2). However, the morphologies observed are identical. Contrarily to other studies [11,12], we never found classical dendrites or columnar grains at the interfaces of the amorphous areas. 
Figure 5. SEM-BEI micrographs of the cross-sectional microstructure evolution of $\mathrm{Fe}_{50} \mathrm{Ni}_{16} \mathrm{Mo}_{6} \mathrm{~B}_{18} \mathrm{Zr}_{10}$ wedged ingot at about the half height area: from the border to the center: uniform amorphous pattern, annular, lenticular grains and needles.

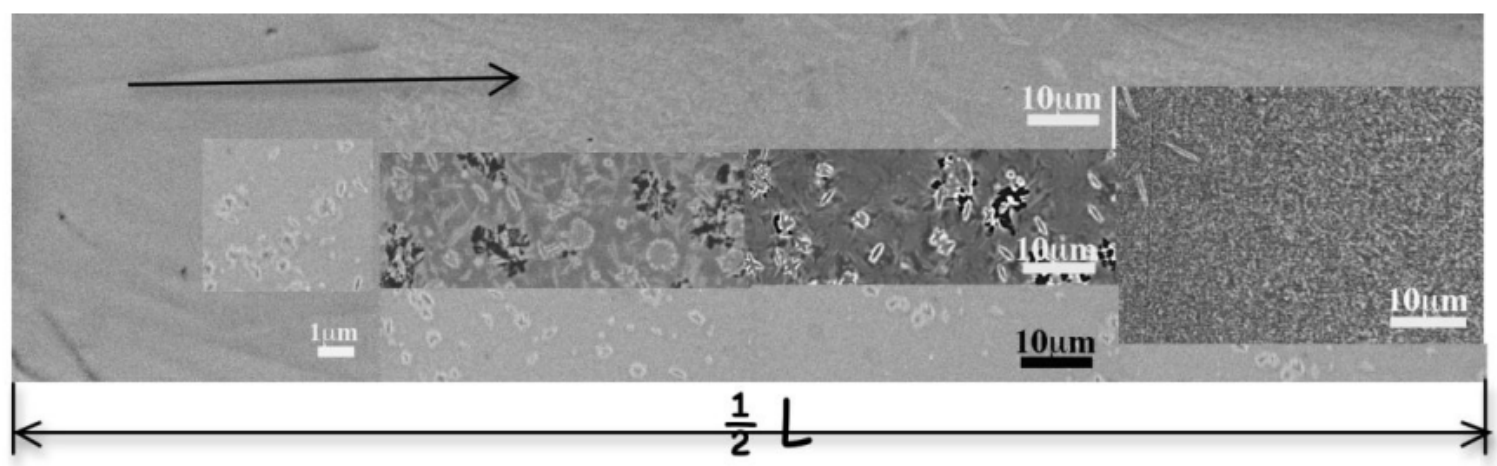

The same microstructural behavior is obtained for $8 \mathrm{~mm}$ diameter ingot (C8). The peripheral areas show the fine acicular microstructure with annular (white circle) and lenticular grains with a smaller size (Figure 6a). In the center, these peculiar morphologies are thicker and their chemical compositions become more visible owing to the contrasted patterns mainly: white, and three variations of grey. They were associated to Fe-B (dark grey) (1), Fe-rich (grey), Fe-Zr (light grey) (2) and Mo-rich (white) (3) compounds. Following their locations within the ingots their compositions are variable like: $17 \%-80 \%$ Fe, $6 \%-16 \% \mathrm{Ni}, 0.5 \%-46 \% \mathrm{Mo}, 4 \%-54 \% \mathrm{Zr}$. The white phases are complex with modulation of Mo proportions with the three others metallic atoms as follows: (Fe-Mo)-rich in the $\mathrm{C} 8$ and $\mathrm{W}$ with respectively $46 \% \mathrm{Mo}, 43 \% \mathrm{Fe}$ and $22 \% \mathrm{Mo} 49 \% \mathrm{Fe}, 15 \% \mathrm{Zr}, 14 \% \mathrm{Ni}$; (Fe-Ni)-rich in $\mathrm{P}$ with $63 \% \mathrm{Fe}$, $23 \% \mathrm{Ni}$, Mo and $\mathrm{Zr}$ at about 7\%. Both composition and morphology indicate decreased atomic mixing and probably prominent atomic diffusion towards the center of the ingot, which can be related to the decrease of the cooling rate. The XRD patterns of one of the cross section of the $\mathrm{W}$ are presented in Figure 7. All the peaks are broader and are attributed to Fe $\alpha$, orthorhombic (o) and tetragonal (t) $\mathrm{Fe}_{3} \mathrm{~B}$, c- $\mathrm{Fe}_{2} \mathrm{Zr}$, c-BMo and potential crystalline c-[Fe, Ni], c- $\mathrm{Fe}_{x} \mathrm{Ni}_{23}{ }_{-x} \mathrm{~B}_{6}, \mathrm{c}-\mathrm{Fe}_{2} \mathrm{Mo}_{3}$ phases. The multiplicity of phases can be attributed to the freedom of the atoms in the liquid to form either stoichiometric or non-stoichiometric groups, which will be present in the solid as stable or/and metastable crystalline phases. The groups of compounds formed by Fe, Mo, $\mathrm{Zr}$ are revealed on the EDS maps.

Figure 6. SEM-BEI micrographs of $8 \mathrm{~mm}$ diameter $\mathrm{Fe}_{50} \mathrm{Ni}_{16} \mathrm{Mo}_{6} \mathrm{~B}_{18} \mathrm{Zr}_{10}$ ingot processed by injection casting. (a) Fine acicular structure of the skin area; (b) Coarse acicular structure in the central area.

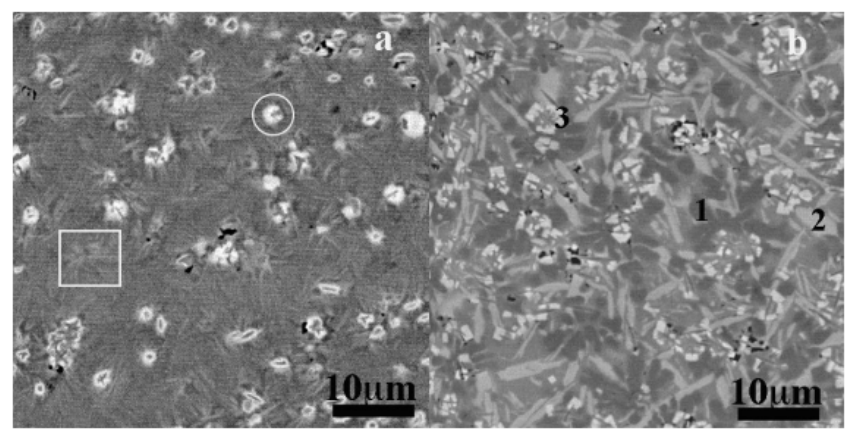


Figure 7. XRD patterns of $\mathrm{Fe}_{50} \mathrm{Ni}_{16} \mathrm{~B}_{18} \mathrm{Mo}_{6} \mathrm{Zr}_{10}$ (Zr2) wedged ingot selected cross section.

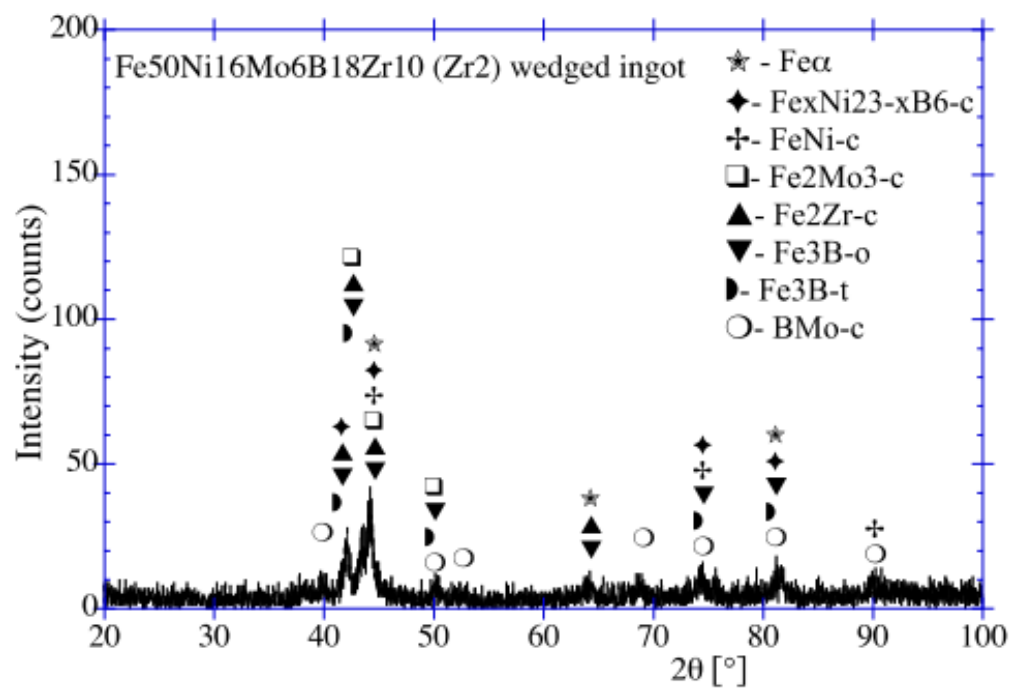

Figure 8 reports the distribution of these atoms in the microstructure of a $10 \mathrm{~mm}$ ingot $(\mathrm{C} 10)$ taken close to the skin area. The SEM-BEI image associated to the chemical maps depicts distorted, twisted lamella. The lines on the image are for guiding eyes. The Fe-rich and Zr-rich portions localizations appear clearly on the maps. There are undoubtedly phases in separation, confirmed by EDS-maps from other part of the sample (see also Figure S3) that are less discernable in the amorphous phase (see Figure S4). The wavelength of the lamella, measured -ridge to ridge- is about 1-3 $\mu \mathrm{m}$ and the visible length is about $14-20 \mu \mathrm{m}$. Comparing the microstructures of the ingots, it is suggested that one morphology occurs during the solidification of glass-forming Zr2 melt: a lamellae. The needles are the product of the lamella's deformation, twisting, division and fragmentation. The annular and lenticular grains are the cross sections of the needles respectively following their width and length. The annular grain is the cut following a plane with variable tilt directions on a bunch of meeting needles. See the white square in Figure 6a as a proof of the above description of the annular grain. This acicular structure is already observed in the $\mathrm{Zr}-\mathrm{Cu}$ based glass-forming alloys [13] and the stacking of lamella is well known in the crystallization of polymers materials as spherulites [14]. It can be assert that the spherulites in crystallized iron-based amorphous alloys have similar features [15]. The twisting of the lamellae in this case can be attributed to surface corrugation with predominantly irregular wavelengths corresponding to the measured distances of about 1-3 $\mu \mathrm{m}$. Corrugations have been observed on fracture surfaces of some BMGs [16-18] with wavelength of about $80 \mathrm{~nm}$ that are interpreted as energy dissipating mechanism during the fracture. We can assert that the same phenomenon occurs during the solidification of melt, the excess thermal energy would be evacuated via interfaces of strained lamella. Transversal interfaces as banding of the lamella are also observed on some micrographs (not shown) taken along the skin area of the ingot where the cooling rate is higher. To our knowledge it is the first time that lamella corrugations are reported in glass forming alloy microstructure.

The microstructures of the three ingots cast with different cooling rate exhibit a unique morphology, lamellae or needle. This indicates that the $\mathrm{Fe}_{50} \mathrm{Ni}_{16} \mathrm{Mo}_{6} \mathrm{~B}_{18} \mathrm{Zr}_{10}$ glass-forming alloy's solidification mechanism is unique suggesting that the glass structure also will be built by lamella. 
Figure 8. SEM-BEI image and SEM-EDS maps of Fe, $\mathrm{Zr}$ and Mo atoms in the $10 \mathrm{~mm}$ diameter $\mathrm{Fe}_{50} \mathrm{Ni}_{16} \mathrm{Mo}_{6} \mathrm{~B}_{18} \mathrm{Zr}_{10}$ ingot quenched in cold water.

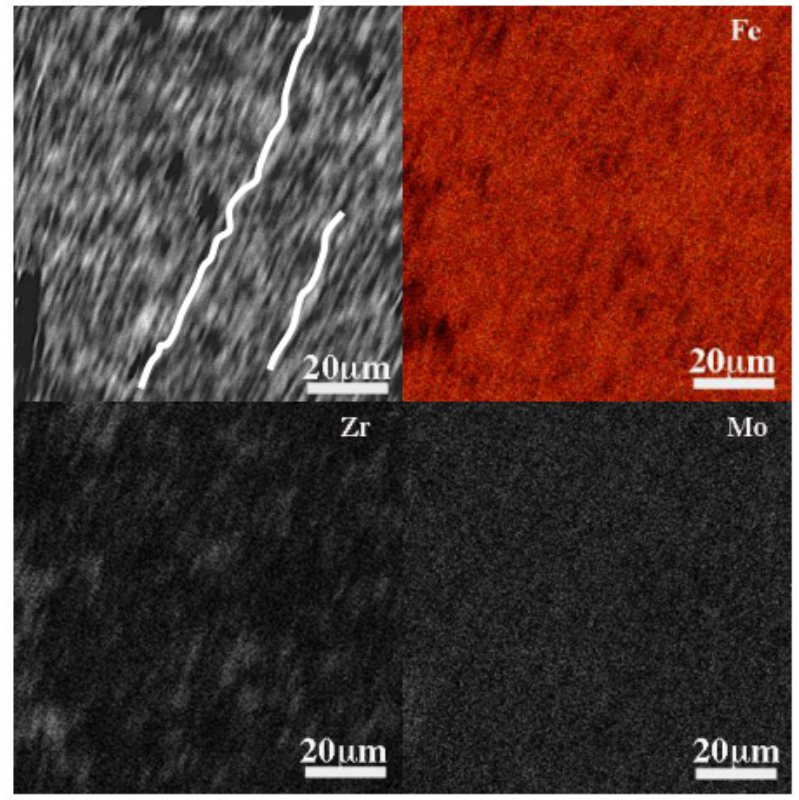

2.5. Structure and Thermal Behaviors of $\mathrm{Fe}_{50} \mathrm{Ni}_{16} \mathrm{Mo}_{6} \mathrm{~B}_{18} \mathrm{Zr}_{10}$ (Zr2) and $\mathrm{Fe}_{66} \mathrm{Mo}_{6} \mathrm{~B}_{18} \mathrm{Zr}_{10}$ (Zr3) BMG Strips: Wrinkled Surfaces

Figure 9a reports XRD patterns of the $\mathrm{Fe}_{66} \mathrm{Mo}_{6} \mathrm{~B}_{18} \mathrm{Zr}_{10}$ (Zr3) BMG strip. Peaks of crystalline phase attributed to $\mathrm{Fe} \alpha$ are observed over the amorphous characteristic halo. DSC curve of Zr3 in Figure 9 shows glass transition at about $853 \mathrm{~K}$ and onset crystalline peak at about $932 \mathrm{~K}$ (Table 1). Despite, the crystalline peaks, the material is basically amorphous, in agreement with the observed microstructure in Figure 5. The peripheral area of $\mathrm{W}$ indicates that the composition with $10 \%$ can form at least a bulk of about 1-1.5 mm thickness. The strip has a thickness of about $0.55 \mathrm{~mm}$. The occurrence of the crystalline peaks may be attributed to casting procedure owing to the melt injection that generates several melt streams and filets. These effects are observed on the surface of the as-cast materials (see Figures S5 and S6). Comparison of $\mathrm{Zr} 3$ to $\mathrm{Zr} 2$ specifies the incidence of Ni alloying atoms on the GFA of the alloys. The reduction of $\mathrm{Ni}$ and its final suppression in the alloy's composition are likely favorable to GFA as is exemplified in the DSC curves (Figure 9b). The Zr3 alloy shows more thermal stability as the characteristic parameters are shifted toward higher temperatures. Although, $\mathrm{Zr} 2$ shows also good apparent GFA, it yields poor strip and during one of the processing, after some BMG pastilles, a part of the melt went out leaving a residual solid in the crucible. The structural effect of the $\mathrm{Ni}$ in the alloy is not well understood. It cannot assert whether this incidence is on atomic groups formation that is on the crystalline phases formation by association with others alloying atoms, for instance $\mathrm{Zr}$ and $\mathrm{B}$ or on the acicular morphology. Investigations are in progress to clarify this observation. In contrary, $\mathrm{Zr} 3$ gives good strip; $200 \mathrm{~mm}$ long, $25 \mathrm{~mm}$ and $0.55 \mathrm{~mm}$ thick. To locate the crystalline phases on the surface of the strip, SEM observations were performed. 
Figure 9. (a) $\mathrm{XRD}$ patterns of $\mathrm{Fe}_{50} \mathrm{Ni}_{16} \mathrm{Mo}_{6} \mathrm{~B}_{18} \mathrm{Zr}_{10}$ (Zr2) strip; (b) DSC curves of $\mathrm{Fe}_{50} \mathrm{Ni}_{16} \mathrm{Mo}_{6} \mathrm{~B}_{18} \mathrm{Zr}_{10}(\mathrm{Zr} 2)$ and $\mathrm{Fe}_{66} \mathrm{Mo}_{6} \mathrm{~B}_{18} \mathrm{Zr}_{10}(\mathrm{Zr} 3)$ strips with $\mathrm{Fe}_{40} \mathrm{Ni}_{38} \mathrm{Mo}_{4} \mathrm{~B}_{18}(\mathrm{Pr})$ ribbon.
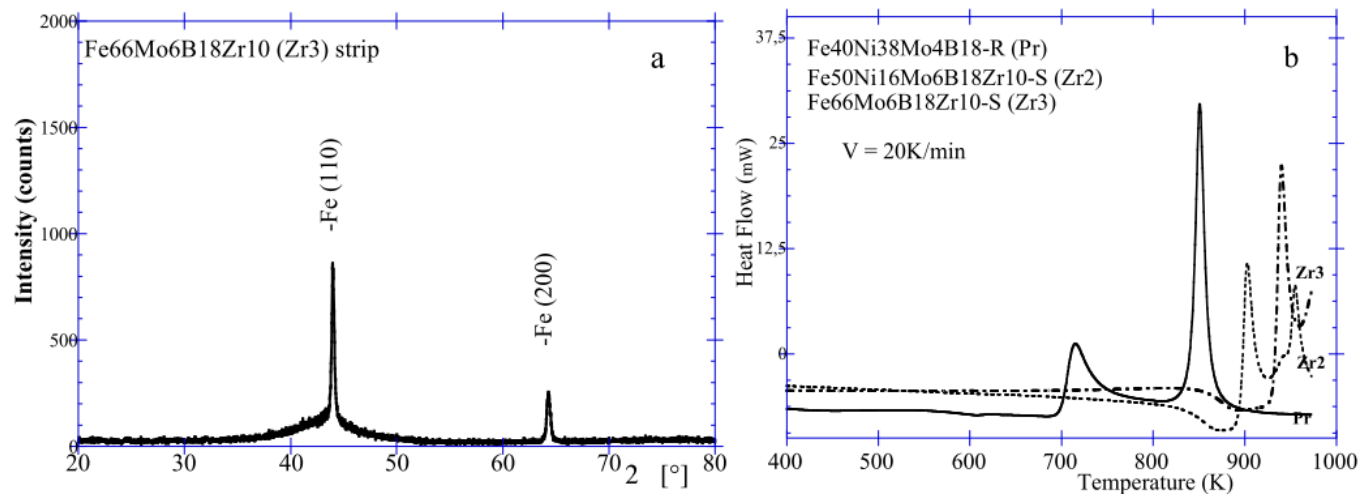

Figure 10. (a) SEM-SEI micrograph of wrinkles on as cast surface of $\mathrm{Fe}_{66} \mathrm{Mo}_{6} \mathrm{~B}_{18} \mathrm{Zr}_{10}$ (Zr3) BMG strip: note the polyhedral-like grains; (b) SEM-BEI micrograph of as cast surface of $\mathrm{Fe}_{66} \mathrm{Mo}_{6} \mathrm{~B}_{18} \mathrm{Zr}_{10}$ (Zr3) BMG strip; needles and wrinkles; (c) SEM-BEI image of wrinkles presumably under two strain directions: $\varepsilon_{1}$ and $\varepsilon_{2}$; (d) Sketch showing the wrinkling and the serration (discontinuous line) on the surface of the BMG; $\lambda$ wrinkle wavelength, $h$ wrinkle amplitude, $t$ surface thickness.

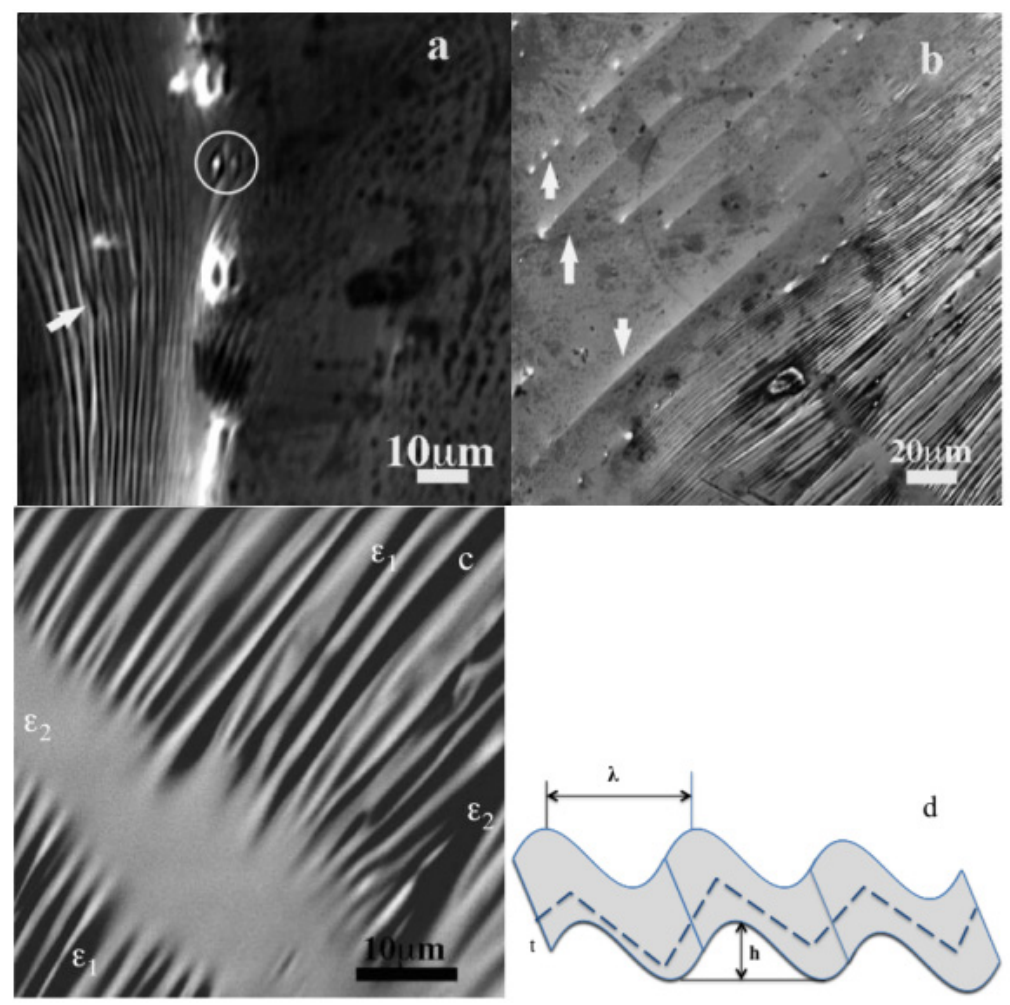

The microstructure of the $\mathrm{Zr} 3$ surface is reported in Figure 10. While neither contrast nor pattern can help find the crystalline phase, wrinkles (white arrow) and peculiar four-axes concave (white circle) and convex polyhedra-like are observed. The convex one is likely the inverse of the concave one, forms by the changing direction of the wrinkles. The wavelengths of the wrinkles are about 1-3 $\mu \mathrm{m}$. In general, the wrinkles have irregular wavelengths, but at least two identical wavelengths are 
found, and some areas can have identical wavelength over 10 waves. The wrinkles exhibit corrugation in the transverse direction appearing as reduction of the wrinkle thickness. The length-groove to groove - of these ripples gives of about 5-15 $\mu \mathrm{m}$. It is the first time observations of such wrinkles are indicated for metallic glass. However, back observations of the surfaces of our other Fe-based and $\mathrm{Zr}-\mathrm{Cu}$ based strips and micrographs from the literature revealed wrinkles on the materials [8]. On other parts of the surface, lines and dots appeared in apparent relation with the underneath wrinkles (Figure 10b, arrowed) as being the merging and the reorganization of wrinkles into needles (see sketch on Figure 10d).

Wrinkles are commonly observed in natural materials $[19,20]$, on stretched membranes and thin films [21-28], in synthetic materials [28,29], on surface growth of oxides [30] and on the solidified surface of liquid [31]. They typically account for applied strains or stress relaxations in the thin materials. Following the submitted in plane strains directions the wrinkles change from single surface corrugations to a complex wrinkled patterns. The wrinkle wavelength $\lambda$ is function of the dimensions and the elastic constants of the membrane (Figure 10d). It can be expressed in function of the Young modulus of the film and the substrate: $\lambda \sim(\mathrm{Lt})^{1 / 2} \varepsilon^{-1 / 4}$, with, $\mathrm{L}$ and $\mathrm{t}$ respectively the length after stretching and the thickness of the membrane and $\varepsilon$ the strain, $\varepsilon=\mathrm{L}-\mathrm{Lo} / \mathrm{Lo}$, Lo initial length [23] for strained membrane or as $\lambda / \mathrm{t}=2 \pi \mathrm{K}^{1 / 3}$ [24], with $K=E_{\mathrm{s}} / 4 E_{\mathrm{m}}\left(1-\pi v_{\mathrm{s}}^{2}\right) ; E_{\mathrm{s}}$ and $E_{\mathrm{m}}$, respectively Young modulus of the substrate and the membrane, $v_{\mathrm{S}}$ the Poisson ratio of the substrate for strain relaxation of the membrane. The wrinkles on the surface of the BMG can be then undoubtedly interpreted as the formation of strained layered thin film as part of the aggregates bulk. The wrinkles are the way the incipient solidified melt relaxes and maintains its dynamic stability. Conservative behavior can also be derived from the convex (depressed) and concave (inflated) (see circle in Figure 10a) polyhedral-like patterns. Their apparition seems to fit equilibrium constraints. Lines and dots (Figure 10b) are likely, respectively, the side and the end (top) view of a needle. It is likely that the wrinkles are inherent to the casting of metallic glass; melt injection or suction that imposes variable flow rates to the melt inducing strains (stresses). The features of the wrinkles in Figure 10a can be associated with viscous-like deformation (smooth apex) [32], as opposed to shear deformation (acute apex) likely related to the needles in upper part of Figure 10b. The description in Figure 10d is also in agreement with the variety of wrinkle patterns like, strip, labyrinth and herringbone. The latter is the evolution of the labyrinth when the strains become anisotropic [33]. There is an association with wrinkle-needle as isotropy-anisotropy that can be hierarchically observed at nanoscale as a liquidsolid demonstration. Since the wrinkled film wavelength's is larger than its thickness, we can conclude that the wrinkled surfaces on the BMG surface are thin layers. Taking a mean thickness of about $2 \mathrm{~mm}$ of the $15 \mathrm{~mm}$ wrinkles gives $\lambda \approx 5 \mathrm{t}$ that yields $\mathrm{Ef} / \mathrm{Es} \approx 1$. In fact, the calculation for more wrinkles indicates Ef/Es values between 1 and 2, which indicate that the layers have close mechanical properties.

In the case of Zr3, wrinkles are also observed within the bulk. These inner wrinkles are probably responsible of the weak response of the material to applied stresses. This strip breaks when it is tightened in a vice. Figure 11 shows the microstructure of the rupture surfaces of a broken strip. Wrinkles with $\lambda$ of about 13-30 $\mu \mathrm{m}$ and amplitudes of about 2-4 $\mu \mathrm{m}$ are observed covered at each end by smooth surfaces. Another wrinkles as braided ropes or nano twisted wires having $\lambda$ of about 150-300 nm, 10 times smaller of the first ones are lying beneath the smooth surface. It is likely the 
result of the merging of the two families of wrinkles as can be observed in the arrowed areas. Bandings observed on these latter are undoubtedly related to the second wrinkling direction. The microstructure in Figure 11a can be qualified as strain induced pattern like that obtained after mechanical test except that in this case the same pattern is observed on the surface of the strip. This similarity of the wrinkled patterns is a proof of the underling identical mechanical mechanism. Figure $11 \mathrm{~b}$ shows another area where shear bands are observed that creates cells pattern. The smallest are constitutive of lamella similar to wrinkles. EDS maps for this area are provided (see Figure S7). Moreover, large wrinkles of about $30 \mu \mathrm{m}$ are also observed as corrugation of the inner bulk surface. These described microstructure characteristic within the bulk of the strip suggests poor strain relieves between the wrinkled interfaces and thus mechanical effects on surface atoms, atomic layers or row of atoms rather than on individual atoms.

Figure 11. (a) SEM-SEI micrograph of wrinkles on a rupture surface of $\mathrm{Fe}_{66} \mathrm{Mo}_{6} \mathrm{~B}_{18} \mathrm{Zr}_{10}$ (Zr3) BMG strip: note the two directional wrinkles (arrowed); (b) SEM-BEI micrograph of a rupture surface of $\mathrm{Fe}_{66} \mathrm{Mo}_{6} \mathrm{~B}_{18} \mathrm{Zr}_{10}(\mathrm{Zr} 3) \mathrm{BMG}$ strip: shear bands and cells.

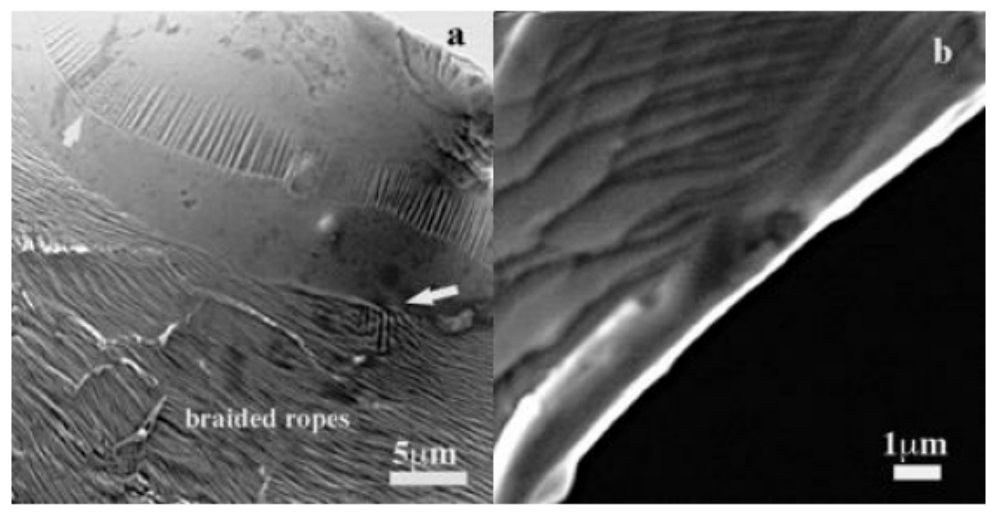

2.6. Microstructure of the Surface of the Residual Solid of $\mathrm{Fe}_{50} \mathrm{Ni}_{16} \mathrm{Mo}_{6} \mathrm{~B}_{18} \mathrm{Zr}{ }_{10}(\mathrm{Zr2})$

As was mentioned in the previous section, residual solid retained in the crucible during one strip processing of $\mathrm{Fe}_{50} \mathrm{Ni}_{16} \mathrm{Mo}_{6} \mathrm{~B}_{18} \mathrm{Zr}_{10}$ after some pastilles and distorted and porous strip. The three materials have different structure but their chemical compositions are close to the master melt. The residual material, appearing as decanted [34] solid surface microstructure is presented in Figure 12. The first observation is that the lines or lamella are similar to that observed in Figure 10a. All the lines are branched, with various directions, that allow them to: form a smooth surface (1), to keep contact with the bulk (2), to adapt to external stresses (3) with its various features (4-7) and to curve (8); the (4) is the side of a flake that forms a flower-like solid with three other flakes around; the (9) is a gathering of the needles' tips; the (6) shows a branching, which is in fact an individual line meeting another one. 
Figure 12. (a,b) SEM-SEI micrographs of the surface of the residual solid in the crucible after injection of $\mathrm{Fe}_{45} \mathrm{Ni}_{21} \mathrm{Mo}_{6} \mathrm{~B}_{18} \mathrm{Zr}_{10}$ alloy.

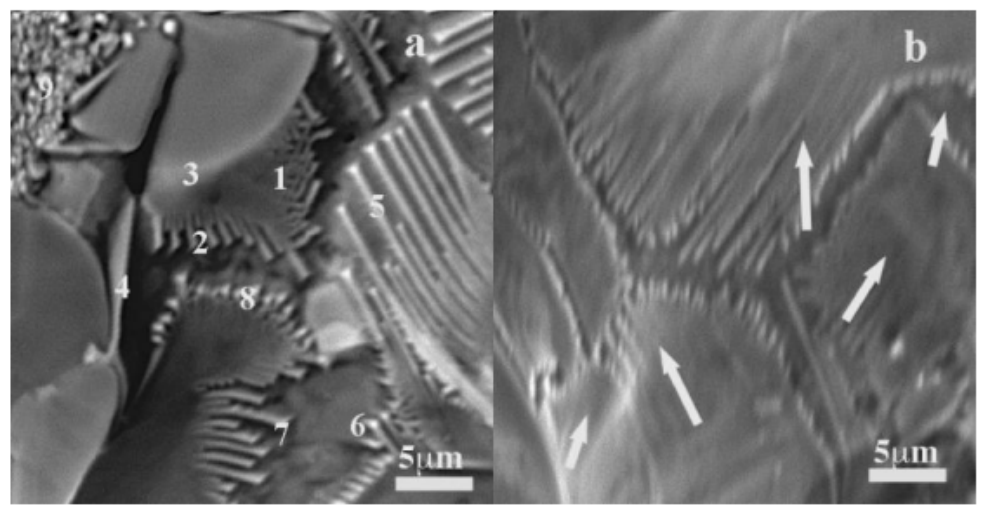

The flakes are formed by the needles, which in turn likely construct a spherulite. Figure $12 \mathrm{~b}$ completes the information about the needles and how they are organized to form a surface adapted to external and internal constraints. In this figure, the arrows indicate the different visible lines directions than can be considered as random. Hexagonal-like grains pattern and grains boundaries are also observed. These latter indicates the change of underneath line direction, this tied to the bulk. Some ripples on the surface suggest wrinkles.

The line observations and their organizations to form surface specify that the needles formation is intrinsic to the glass forming melt. The "decanted" surface allows better observations of the microstructural crystalline phases' morphologies, for instance the branched needles commonly termed as dendrites. Figures 11, 13 and S8 suggest strongly that the wrinkling is not only superficial but also a bulk mechanism, which may be attributed to the morphology of melt filets or filaments.

Figure 13 reports the transmission electron microscope bright field images (TEM-BF) of the $8 \mathrm{~mm}$ diameter (C8) injected ingot. Various kind of needles and details of their constitution are observed in Figure 13a,c-f. Figure 13b presents an amorphous pocket between some needles. The amorphous pattern exhibits a chain of a lozenge-type morphology emerging from needles. This peculiarity is clearly visible on the left of the arrow that indicates the interface between the amorphous zone and crystalline phase oriented in [111] zone axis. This evidences a close relationship between amorphous phase and needle or in other words, the needles are likely the growth morphology of the structural basic unit involved in the amorphous phase. Figure 13c (arrowed) shows the association of needles side by side and head by head, the larger needles having the thickness of about $300 \mu \mathrm{m}$. For instance, that in the bottom of the image is constituted by the merging of smaller needles with variable thicknesses, the measured thinnest is about $20 \mathrm{~nm}$ thick (see Figure S8 for more observations). The bending black contrasts on the image reveal curved needles like bellows observed in Figure 12a (8). Selected area electron diffraction (SAED) patterns in this area indicate the presence of $\mathrm{Fe} \alpha$ and $\mathrm{o}-\mathrm{Fe}_{3} \mathrm{~B}$ (SAED inset Figure 13c) that suggested complex lamellar eutectic structure or acicular eutectic. The symmetrical needle tip is arrow-headed with an angle of about $60^{\circ}$ while the asymmetrical angle scaled to $70^{\circ}$ and $80^{\circ}$. Figure $13 \mathrm{~d}$ shows the second type of needles less thick of about $100 \mathrm{~nm}$ under bulk view. 
Figure 13. TEM-BF micrographs of $\mathrm{Fe}_{50} \mathrm{Ni}_{16} \mathrm{Mo}_{6} \mathrm{~B}_{18} \mathrm{Zr}_{10}$ (C8) thin specimen from the $8 \mathrm{~mm}$ diameter ingot: (a) Image of acicular microstructure; (b) Image of an amorphous pocket; (c) Image of acicular microstructure with bending contrast and dislocations; (d) Image of needles network. (e,f) Image of row of lamellae within a needle and needles crossing angle.
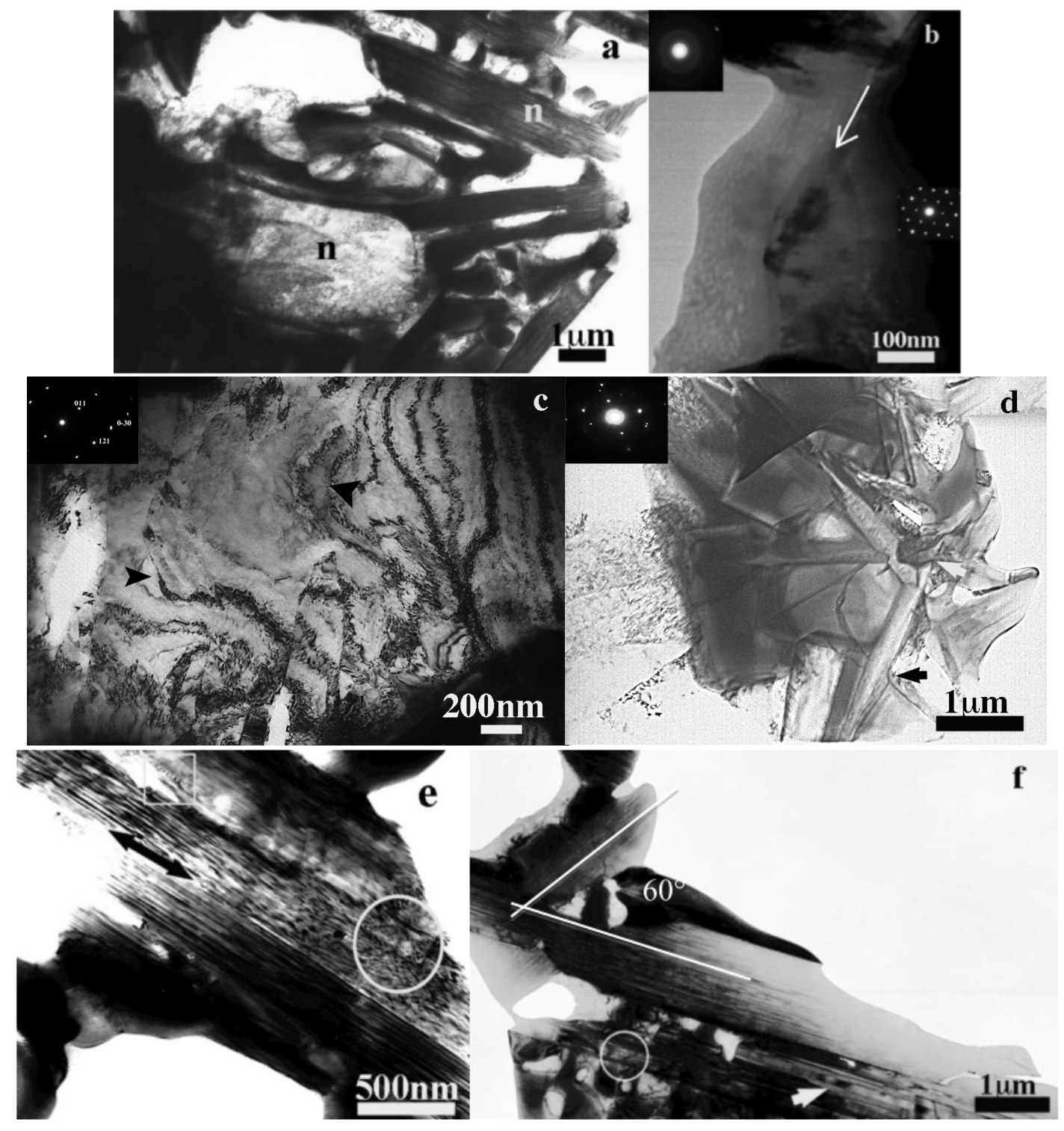

Needles in agreement with observations in Figure 6 cover all the area. Variable tilt plane angle interception of this needles' network area form the annular and the lenticular grains observed in Figures 4-6. Black arrow indicates how the needles assemble like a mechanical shaft and bore. A sketch of this image is shown in Figure 14. Needle (2) goes through (1) that enters (3) and (4) is directed out of the plane of the image. This observation demonstrates a liquid-like behavior, meaning the needles owned their morphologies before solidification. Otherwise, they will not go through but stop at the intersection to form twins. These latter can be observed within the needle (1), which is likely formed by a row of quadratic (see cross section A-A in Figure 14) plates. Moreover, needles (1) and (2) are twisted in Figure 13d. Transversal lamella (see the circle and the square in Figure 13e) is probably the initial state of the quadratic plates. The double arrow in this image shows row of lamella 
building the needle similar to the one in Figure 8. The lamellae thickness is about 10-20 nm compared to $2 \mu \mathrm{m}$ in Figure 8. It is 10 times smaller indicating hierarchical structure. The shaft's morphology and the chain-like organization reveal motion behavior that is consistent with a flow. TEM images show also the overlapping of the needles and the lamellae in Figure 13f (white circle) and the grooves on it (arrow). The underneath eutectic structure can be observed through the lamellae which is about $50 \mathrm{~nm}$ wide. Upper needle constitution is also highlighted with the crossing angle similar to that in the Figure $13 \mathrm{~d}$. These needles are $\mathrm{c}-\mathrm{Fe}_{2} \mathrm{Zr}$ and $\mathrm{c}-\mathrm{Fe}_{3} \mathrm{Zr}$ phases with cell parameters respectively of $a=0.702 \mathrm{~nm}$ and $a=1.175 \mathrm{~nm}$. The third type of needle is shown in Figure 12e, which is likely a $\mathrm{t}-\mathrm{B}_{2}$ Mo crystalline phase with cell parameters $a=0.311 \mathrm{~nm}$ and $c=1.695 \mathrm{~nm}$. The angle of about $60^{\circ}$ between needles in Figure 13f, and c with Figure 14 corresponds to an angle between two $\{0,1,1\}$ and that of $55^{\circ}$ between $\{1,1,0\}$ and $\{1,1,2\}$ for instance. These correspondences will be checked exactly in further studies.

Figure 14. Sketch representing the needles network in Figure 13d.

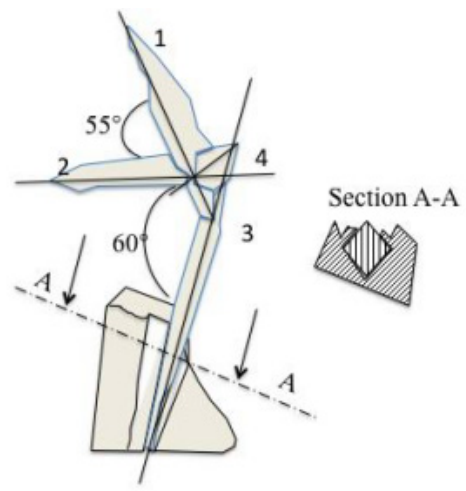

\subsection{First Steps of a Microstructural Model of the Amorphous Structure (MMAS)}

As observed on the SEM micrographs of C8, the acicular microstructure is confirmed by TEM observations and needles details constitution and crystalline phases characterized. The location of the amorphous pocket within needles indicates a solidification rate variation within the liquid during the quenching. The amorphous pattern suggests a hierarchical phenomenon involving thin strained lamella probably about 2-3 atomic layers due to the flow mechanism, the collective motions of atoms. These rippled atomic layers merge to form the amorphous cells that grows into needles or larger lamella following the solidification rate. This latter governs the amorphous process because it is related to the melt flow established by the melt viscosity. Solidification is achieved when the melt flow is close to zero leaving ripples and serration within the material. It is likely that lamella motions generate the flow. Thus, the glass-forming solid microstructure can be imaged as a "mille feuilles", a French cake made up of layered puff pastry. The amorphous material can be compared to a solid composed by broken "mille feuilles".

It is a new look into the amorphous structure that introduces the effective mechanical contributions to the formation of the amorphous solid. For instance, the random network of the needles is the result of the wrinkling of the lamella under random directed strains resembling to the amorphous pattern in Figure $13 \mathrm{~b}$ similar to that shown in white circle in Figure $13 \mathrm{e}$ at nanoscale and in Figure 9 at microscale. 
The microstructural model of amorphous structure (MMAS) states that: (i) the mechanical effects on atomic scale are on chain of atoms and atomic layer than on single atoms resulting in wrinkled atomic layers (mesowrinkles); (ii) the mixing and merging network of the wrinkled atomic layers or lamella form the cells network (nanowrinkles); (iii) the association and organization of cells (c) form wrinkled lamella (microwrinkles) that are constitutive of BMG material. Thus, it is necessary to generated enough stress relieves on the wrinkles surface during casting to obtain larger diameter and avoid brittleness. The mechanical effect on atomic layer can be observed on the sketch in Figure 15a. A wrinkled atomic layer can be easily constructed within the classical representation of disordered atomic organization. The wrinkling of the atomic layers can follow the description in Figure 15b where a three-axis system can be connected to the layers; the z-axis represents the thickness $t$ of the layers. Figure 16 presents the mechanism of the formation of the lozenge-type cell - in fact a polyhedron-by the crossing and the merging of two wrinkles, the multiple wrinkles network (a), and its representation on the amorphous pattern of the Figure 13b. Since the wrinkled surfaces are formed by lamella, the cell (c) is a bunch of wrinkled atomic layers, its SEAD pattern would shows rings like a curved atomic sheets [35]. The various wrinkles thickness has to be determined in order to estimate the Young modulus of the layers according to the scaling laws described by Cerda et al. [36] or other laws. This must be done also at atomic level on high-resolution electron transmission images. In the case of these latter, the observation of the same wrinkling patterns and associated peculiar features in optical micrographs (Figure 13b) would undoubtedly help depict the right microstructure of amorphous phase. The SAED rings and the X-rays haloes would be correlated to the wavelengths of the wrinkles at atomic scale.

Figure 15. (a) Sketch showing the classical representation of crystalline and amorphous atomic organizations; (b) Sketch showing the wrinkling of atomic layers under strains and the direct axis that can be linked to the wrinkled atomic layers.
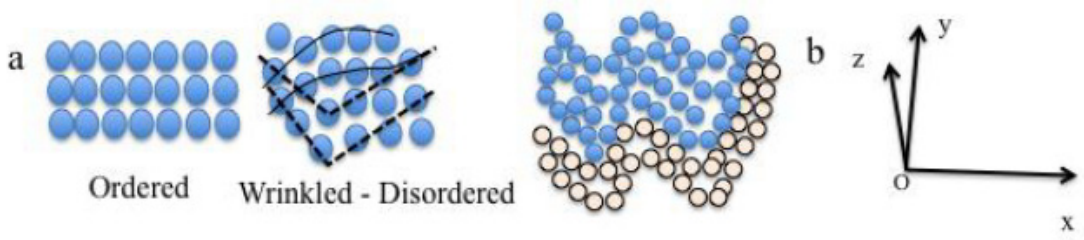

Figure 16. (a) Sketch showing crossing of two wrinkled surfaces to create a cell (c), the constitution of the cell (c) (following Figure 11a(1)) with lower lengthscale wrinkles and wrinkles network; (b) Equivalent representation on the amorphous pattern in Figure 13b.

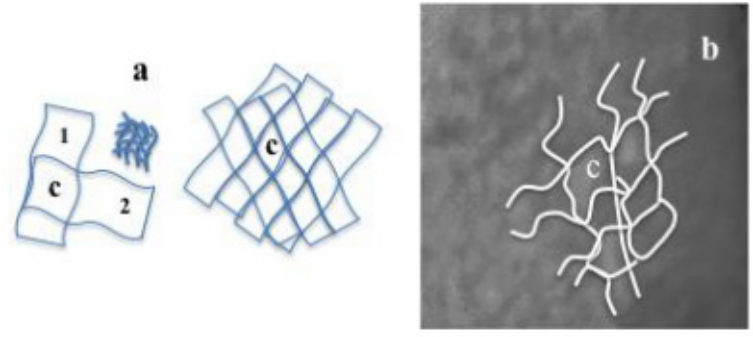


This proposed description of the MMAS is consistent with the graphene and carbon nanotube buckling under stresses or strains [37-40]. It is also in agreement with observations of wrinkled sheets of $\sim 65-85 \mathrm{~nm}$ with central units of semi ordered atomic layer of about 3-8 $\mathrm{nm}$ in amorphous FeS [29]. In other words, if the amorphous material were exfoliated to a single atomic layer, one would find a wrinkled layer. It is presumably the mechanism of the amorphous formation by mechanical alloying techniques. The wrinkling would account for single or multiple elastic strains or shears. The stacking of the wrinkled layers (mille feuilles) would form the amorphous structure with the lozenge-type cells pattern. The atomic organization of this latter will be described in further papers.

\section{Experimental Section}

The alloys have been prepared from components of high purity: $\mathrm{Fe}>99.9 \%$ (purified by four zones melting), Ni (99.9\%), Mo (99.95\%), B (99.5\%), and Zr (99.96\%). Pre-alloying of the components to obtain master ingots was carried out by high frequency (HF) induction melting in a water-cooled copper boat. The following melting was achieved also by HF induction. The ribbons were rapidly solidified by the planar flow casting technique at a wheel velocity of about $19 \mathrm{~m} / \mathrm{s}$ with constant ejection pressure of about 250 mbar leading to a quenching rate going from $10^{5}$ to $10^{6} \mathrm{~K} / \mathrm{s}$. The ribbons thickness is about $30 \mu \mathrm{m}$ for $\mathrm{Fe}_{45} \mathrm{Ni}_{38} \mathrm{Mo}_{4} \mathrm{~B}_{18}$ and $60 \mu \mathrm{m}$ for $\mathrm{Fe}_{45} \mathrm{Ni}_{21} \mathrm{Mo}_{6} \mathrm{~B}_{18} \mathrm{Zr}_{10}$ and $\mathrm{Fe}_{50} \mathrm{Ni}_{16} \mathrm{Mo}_{6} \mathrm{~B}_{18} \mathrm{Zr}_{10}$ alloys. Wedged and cylindrical and plate ingots were processed by levitation melting in water-cooled copper mold. The cylindrical ingots have about $8 \mathrm{~mm}$ diameter and about $40 \mathrm{~mm}$ length. An ingot of $10 \mathrm{~mm}$ diameter was also processed by cold-water quenching in fuse silica tube at an estimated cooling rate of about $500 \mathrm{~K} / \mathrm{s}$. Strips were obtained by twin roll casting with thickness of about $0.55 \mathrm{~mm}$ at an estimated cooling rate of about $100 \mathrm{~K} / \mathrm{s}$.

Figure 17. Sketch of the processed wedged ingot.

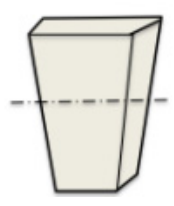

Glassiness and crystalline phases were checked by means of $\mathrm{X}$ rays diffraction using $\mathrm{Cu} \mathrm{K} \alpha$ radiation on a Philips PW 1700 diffractometer. Thermal behavior was investigated using Mettler Toledo DSC $822^{\mathrm{e}}$ scanning differential calorimeter. Microstructures have been studied using both Hitachi scanning electron microscope (SEM) and Jeol CX 100 transmission electron microscope (TEM). The microstructure's chemical compositions were analyzed by energy dispersive X-ray spectroscopy (EDS) in the SEM apparatus where the images are recorded both in the scanning electron image (SEI) and in the backscattered electron image mode (BEI). The specimens for TEM observations were electrolytically thinned in methanol $+30 \%$ nitric acid solution. All chemical compositions reported in this paper are in atomic percent $(\%)$. 


\section{Conclusions}

We have investigated the iron-boron based bulk metallic glasses (BMG) development from precursor $\mathrm{Fe}_{40} \mathrm{Ni}_{38} \mathrm{Mo}_{4} \mathrm{~B}_{18}$ alloy. The addition of $\mathrm{Zr}$ enhances the GFA of the $\mathrm{Fe}_{45} \mathrm{Ni}_{21} \mathrm{Mo}_{6} \mathrm{~B}_{18} \mathrm{Zr}_{10}$, $\mathrm{Fe}_{50} \mathrm{Ni}_{16} \mathrm{Mo}_{6} \mathrm{~B}_{18} \mathrm{Zr}_{10}$, and $\mathrm{Fe}_{66} \mathrm{Mo}_{6} \mathrm{~B}_{18} \mathrm{Zr}_{10}$, which were processed by different casting techniques enabling different cooling rates. Microstructures studies reveal the homogeneity of the glassy-forming melt in terms of the uniform presence of probable crystalline phases that exhibit a unique morphology for various crystalline phases, a needle, when the critical cooling rate for glass formation was not achieved. The observed annular and lenticular grains are the cross sections resulting from the interception of variable tilt angle plane with the needles.

Wrinkles are formed on the surface and within the bulk of the $\mathrm{Fe}_{66} \mathrm{Mo}_{6} \mathrm{~B}_{18} \mathrm{Zr}_{10} \mathrm{BMG}$ strip, characteristic of strained film that can account for the contribution of mechanical conditions inherent to amorphous casting techniques. These observations suggest that the amorphous is like a "mille feuilles" composed with wrinkled atomic layers. Random anisotropic nano-wrinkles would produce diffraction patterns similar to that of amorphous structure.

A microstructural model of amorphous structure (MMAS) is proposed with three main features: (i) the mechanical effects on atomic scale are on chain of atoms which are wrinkled (mesowrinkles); (ii) the merging of the wrinkled atomic layers to form lozenge-type cells network (nanowrinkles); (iii) the association and organization of cells to form wrinkled lamella (microwrinkles) constitutive of BMG material.

The atomic arrangements within the lozenge type cells will be described in further publications.

\section{Acknowledgments}

The authors are grateful to Patrick Ochin for the alloys processing, and also to Noble Akam for manuscript correction and discussions.

\section{References and Notes}

1. Inoue, A. Stabilization of metallic supercooled liquid and bulk amorphous alloys. Acta Mater. 2000, 48, 269-306.

2. Peker, A. Liquidmetal inventor: Apple will use it in a "breakthrough product". Available online: http://www.businessinsider.com/liquidmetal-inventor-atakan-peker-apple-will-use-it-in-abreakthrough-product-2012-5 (accessed on 1 May 2012).

3. Inoue, A.; Zhang, T.; Koshiba, H. New bulk amorphous Fe-(Co,Ni)-M-B (M = Zr, Hf, Nb, Ta, Mo, W) alloys with good soft magnetic properties. J. Appl. Phys. 1998, 8, 6326-6328.

4. Smith, C.S. A History of Martensite: Early Ideas on the Structure of Steel. In Martensite, A tribute to Morris Cohen; Olson, G.B., Owen, W.S., Eds.; ASM International: Materials Park, OH, USA, 1992; pp. 21-39.

5. Ma, L.; Wang, L.; Zhang, T.; Inoue, A. Fe-based metallic glass with significant supercooled liquid region over 90 K. J. Mat. Sci. Lett. 1998, 17, 1893-1895.

6. Mizgalski, K.P.; Inal, O.T.; Yost, F.G.; Karnowsky, M.M. Characterization of crystallization in Metglas 2826 MB alloy. J. Mat. Sci. 1981, 16, 3357-3364. 
7. Aboki, A.M.; Harmelin, M.; Bouquet, G.; Portier, R. Internal friction evolution during crystallization of $\mathrm{Fe}_{40} \mathrm{Ni}_{38} \mathrm{Mo}_{4} \mathrm{~B}_{18}$ amorphous alloys. Scr. Metall. Mater. 1990, 24, 1873-1878.

8. Jones, H. Splat cooling and metastable phases. Rep. Prog. Phys. 1973, 36, 1427-1497.

9. Aboki, T.M.A.; Baudu, S.; Robbiola, L.; Ochin, P. Formation of sigma-like Mo-rich ternary phase in $\mathrm{Fe}_{40} \mathrm{Ni}_{38} \mathrm{Mo}_{4} \mathrm{~B}_{18}$ glass forming alloy. Scr. Mater. 2000, 43, 453-458.

10. Jones, H. reported in this review [8] a paper of Sarjeant and Roy (1968), page 1468, that derived a simple expression for critical cooling rate for amorphous formation $\mathrm{d} T / \mathrm{d} t \approx K \mathrm{R} T^{2} / \eta \mathrm{V}$ from the Turnbull's formalism of nucleation and growth: $K$, constant; $\mathrm{R}$, gas constant; $T$, melting temperature; $\eta$, viscosity; $V$, molar volume of the liquid. This expression is in agreement with the experiment that shows that the critical cooling rate decreases with the increase of the viscosity.

11. Inoue, A. Bulk Amorphous Alloys. In Amorphous and Nano-Crystalline Materials Preparation, Properties, and Applications; Inoue, A., Hashimoto, K., Eds.; Springer-Verlag: Berlin, Germany, 2001; pp. 1-48.

12. Boettinger, W.J. The Effect of Alloy Constitution and Crystallization Kinetics on the Formation of Metallic Glass. In Proceedings of the International Conference on Rapidly Quenched Metals, Sendai, Japan, 1981; pp. 99-102.

13. Aboki, A.B.; Brisset, F.; Souron, J.P.; Dezellus, A.; Plaindoux, P. Microstructure studies of $\mathrm{Zr}_{65} \mathrm{Cu}_{17.5} \mathrm{Al}_{7.5} \mathrm{Ni}_{10}$ and $\mathrm{Zr}_{65} \mathrm{Cu}_{15} \mathrm{Al}_{10} \mathrm{Ni}_{10}$ glass forming alloys: Phase morphologies and undercooled melt solidification. Intermetallics 2008, 16, 615-624.

14. Sasaki, S.; Sakaki, Y.; Takahara, A.; Kajiyama, T. Microscopic lamellar organization in high-density polyethylene banded spherulites studied by scanning probe microscopy. Polymer 2002, 43, 3441-3446.

15. Zaluska, A.; Matyja, H. Rapid heating of Fe-Si-B metallic glass, J. Mat. Sci. Lett. 1983, 2, 729-732.

16. Trexler, M.M.; Thadhani, N.N. Mechanical properties of bulk metallic glasses. Prog. Mat. Sci. 2010, 55, 759-839.

17. Wang, G.; Han, Y.N.; Xu, X.H.; Ke, F.J.; Han, B.S.; Wang, W.H. Ductile to brittle transition in dynamic fracture of brittle bulk metallic glass. J. Appl. Phys. 2008, 103, 093520:1-093520:5.

18. Jiang, M.Q.; Meng, J.X.; Gao, J.B.; Wang, X.-L.; Rouxel, T.; Keryvin, V.; Ling, Z.; Dai, L.H. Fractal in fracture of bulk metallic glass. Intermetallics 2010, 18, 2468-2471.

19. Mei, Y.; Kiravittaya, S.; Harazim, S.; Schmidt, O.G. Principles and applications of micro and nanoscale wrinkles. Mat. Sci. Eng. R 2010, 70, 209-224.

20. Bensimon, D.; Mutz, M.; Gulik, T. Wrinkling transition in polymerized membranes. Phys. $A$ 1993, 194, 190-198.

21. Lecieux, Y.; Bouzidi, R. Numerical wrinkling prediction of thin hyperelastic structures by direct energy minimization. Adv. Eng. Softw. 2012, 50, 57-68.

22. Chan, E.P.; Crosby, A.J. Spontaneous formation of stable aligned wrinkling patterns. Soft Matter 2006, 2, 324-328.

23. Nayyar, V.; Ravi-Chandar, K.; Huang, R. Stretch-induced stress patterns and wrinkles in hyperelastic thin sheets. Int. J. Solids Struct. 2011, 48, 3471-3483.

24. Groenewold, J. Wrinkling of plates coupled with soft elastic media. Phys. A 2001, 298, 32-45. 
25. Mougin, K.; Vonna, L.; Vidal, L.; Haidara, H. Spontaneous growth of self-relief wrinkles in freely floating lipid-based nanomembranes, formed on a reactive bath of polyoxometalate aqueous solution. J. Colloid Interface Sci. 2010, 345, 377-383.

26. Yu, C.; Jiang, H. Forming wrinkled stiff films on polymeric substrates at room temperature for stretchable interconnects applications. Thin Solid Films 2010, 519, 818-822.

27. Zhu, L.; Susaca, D.; Teoa, M.; Wong, K.C.; Wong, P.C.; Parsons, R.R.; Bizzotto, D.; Mitchell, K.A.R. Investigation of $\mathrm{CoS}$ 2-based thin films as model catalysts for the oxygen reduction reaction. J. Catal. 2008, 258, 235-242.

28. Amini, S.; Abbaschian, R. Synthesis of curved graphene layers on metallic dendrites. Mat. Lett. 2012, 88, 129-131.

29. Csákberényi-Malasics, D.; Rodriguez-Blanco, J.D.; Kis, V.K.; Rečnik, A.; Liane, G.; Benning, L.G.; Pósfai, M. Structural properties and transformations of precipitated FeS. Chem. Geol. 2012, 294-295, 249-258.

30. Clarke, D.R. Stress generation during high-temperature oxidation of metallic alloys. Curr. Opin. Solid State Mat. Sci. 2002, 6, 237-244.

31. Ueda, M.; McCaldin, J.O.; Shima, R. Crystallization of substrate-confined liquid indium. Thin Solid Films 1982, 98, 241-247.

32. Greer, J.R.; de Hosson, J.T.M. Plasticity in small-sized metallic systems: Intrinsic versus extrinsic size effect. Prog. Mat. Sci. 2011, 56, 654-724.

33. Huang, Z.Y.; Wong, W.; Suo, Z. Nonlinear analyses of wrinkles in a film bonded to a compliant substrate. J. Mech. Phys. Solids 2005, 53, 2101-2118.

34. Chalmers, B. Principles of Solidification; John Wiley \& Sons, Inc: New York, NY, USA, 1964; pp. 162-163.

35. Im, S.H.; Huang, R. Wrinkle patterns of anisotropic crystal films on viscoelastic substrates. J. Mech. Phys. Solids 2008, 56, 3315-3330.

36. Cerda, E.; Mahadevan, L. Geometry and physics of wrinkling, Phys. Rev. Lett. 2003, 90, 074302.

37. Sealy, C. Ripples in graphene: It's all in the bonds. Mat. Today 2007, 10, 9.

38. Czigany, Z.; Hultman, L. Interpretation of electron diffraction patterns from amorphous and fullerene-like carbon allotropes. Ultramicroscopy 2010, 110, 815-819.

39. Choudhary, S.K.; Gupta, A.K. Scanning tunneling microscopy and spectroscopy study of charge inhomogeneities in bilayer graphene. Solid State Commun. 2011, 151, 396-399.

40. Kuilla, T.; Bhadrab, S.; Yaoa, D.; Kimc, N.H.; Bosed, S.; Lee, J.H. Recent advances in graphene based polymer composites. Prog. Polym. Sci. 2010, 35, 1350-1375.

(C) 2013 by the authors; licensee MDPI, Basel, Switzerland. This article is an open access article distributed under the terms and conditions of the Creative Commons Attribution license (http://creativecommons.org/licenses/by/3.0/). 